\title{
Potential oxygen consumption and community composition of sediment bacteria in a seasonally hypoxic enclosed bay
}

\author{
Fumiaki Mori ${ }^{\text {Corresp., } 1,2,3}$, Yu Umezawa ${ }^{4}$, Ryuji Kondo $^{5}$, Gregory N Nishihara ${ }^{1,2}$, Minoru Wada ${ }^{1}$ \\ ${ }^{1}$ Graduate School of Fisheries and Environmental Sciences, Nagasaki University, Nagasaki, Nagasaki, Japan \\ 2 Institute for East China Sea Research, Organization for Marine Science and Technology, Nagasaki University, Nagasaki, Nagasaki, Japan \\ 3 Kochi Institute for Core Sample Research, Japan Agency for Marine-Earth Science and Technology (JAMSTEC), Kochi, Japan \\ 4 Department of Environmental Science on Biosphere, Tokyo University of Agriculture and Technology, Tokyo, Japan \\ 5 Department of Marine Science and Technology, Fukui Prefectural University, Fukui, Japan \\ Corresponding Author: Fumiaki Mori \\ Email address: morifu@jamstec.go.jp
}

The dynamics of potential oxygen consumption at the sediment surface in a seasonally hypoxic bay were monitored monthly by applying a tetrazolium dye (2-(4-iodophenyl)-3-(4nitrophenyl)-5-phenyl-2H-tetrazolium chloride [INT]) reduction assay to intact sediment core samples for two consecutive years (2012-2013). Based on the empirically determined correlation between INT reduction (INT-formazan formation) and actual oxygen consumption of sediment samples, we inferred the relative contribution of biological and non-biological (chemical) processes to the potential whole oxygen consumption in the collected sediment samples. It was demonstrated that both potentials consistently increased and reached a maximum during summer hypoxia in each year. For samples collected in 2012, amplicon sequence variants (ASVs) of the bacterial 16S rRNA genes derived from the sediment surface revealed a sharp increase in the relative abundance of sulfate reducing bacteria toward hypoxia. In addition, a notable shift in other bacterial compositions was observed before and after the INT assay incubation. It was Arcobacter (Arcobacteraceae, Campylobacteria), a putative sulfur-oxidizing bacterial genus, that increased markedly during the assay period in the summer samples. These findings have implications not only for members of Delta- and Gammaproteobacteria that are consistently responsible for the consumption of dissolved oxygen (DO) year-round in the sediment, but also for those that might grow rapidly in response to episodic DO supply on the sediment surface during midst of seasonal hypoxia. 
$7 \quad{ }^{1}$ Graduate School of Fisheries and Environmental Sciences, Nagasaki University 851-2213

8 Nagasaki, Japan.

9 Institute for East China Sea Research, Organization for Marine Science and Technology,

\section{Potential oxygen consumption and community composition of sediment bacteria in a} seasonally hypoxic enclosed bay
Fumiaki Mori ${ }^{1,2, \dagger}, *$, Yu Umezawa ${ }^{3}$, Ruji Kondo ${ }^{4}$, Gregory N. Nishihara ${ }^{1,2}$, Minoru Wada ${ }^{1}$

\section{Nagasaki University, Nagasaki 851-2213, Japan.}

${ }^{3}$ Department of Environmental Science on Biosphere, Tokyo University of Agriculture and Technology, Tokyo 183-8509, Japan.

${ }^{4}$ Department of Marine Science and Technology, Fukui Prefectural University, Fukui 917-0003, Japan.

6 †Present address: Kochi Institute for Core Sample Research, Japan Agency for Marine-Earth Science and Technology (JAMSTEC), Kochi, 783-8502, Japan

\section{8}

*Corresponding author:

$20 \quad$ Fumiaki Mori ${ }^{1,2, \dagger, *}$

$21 \quad$ Email Address: morifu@jamstec.go.jp 


\section{Abstract}

The dynamics of potential oxygen consumption at the sediment surface in a seasonally hypoxic bay were monitored monthly by applying a tetrazolium dye (2-(4-iodophenyl)-3-(4-nitrophenyl)5-phenyl-2H-tetrazolium chloride [INT]) reduction assay to intact sediment core samples for two consecutive years (2012-2013). Based on the empirically determined correlation between INT reduction (INT-formazan formation) and actual oxygen consumption of sediment samples, we inferred the relative contribution of biological and non-biological (chemical) processes to the potential whole oxygen consumption in the collected sediment samples. It was demonstrated that both potentials consistently increased and reached a maximum during summer hypoxia in each year. For samples collected in 2012, amplicon sequence variants (ASVs) of the bacterial 16S rRNA genes derived from the sediment surface revealed a sharp increase in the relative abundance of sulfate reducing bacteria toward hypoxia. In addition, a notable shift in other bacterial compositions was observed before and after the INT assay incubation. It was Arcobacter (Arcobacteraceae, Campylobacteria), a putative sulfur-oxidizing bacterial genus, that increased markedly during the assay period in the summer samples. These findings have implications not only for members of Delta- and Gammaproteobacteria that are consistently responsible for the consumption of dissolved oxygen (DO) year-round in the sediment, but also for those that might grow rapidly in response to episodic DO supply on the sediment surface during midst of seasonal hypoxia.

Keywords: sediment oxygen consumption, bacterial community composition, hypoxia, coastal hypoxia, enclosed bay, Arcobacter, INT 


\section{Introduction}

Surface sediment plays an important role in the oxygen cycle of benthic ecosystems due to the large number of microbes (bacteria) and oxygen reactive reductants it contains. A study by Rivera et al. (2010) estimated that up to $81 \%$ of the total oxygen consumption below the pycnocline could be ascribed to sediment oxygen consumption (SOC) in coastal seas. Measuring SOC in situ has been widely conducted to quantify the extent of sediment metabolism and has contributed to expanding our understanding of aquatic bottom environments (Zimmerman \& Benner, 1994; Rowe, Kaegi \& Morse, 2002). However, the direct measurement of SOC may underrepresent the biogeochemical processes that contribute to oxygen dynamics in a hypoxic region, as it typically declines under hypoxic conditions due to the lower availability of oxygen in the surface sediment. When dissolved oxygen (DO) in the water overlying sediment becomes anoxic, oxygen consumption is not practically measurable. However, anaerobic heterotrophic bacteria mediate the degradation of organic matter, and the resultant metabolic products, including ammonium $\left(\mathrm{NH}_{4}{ }^{+}\right)$, iron (II) $\left(\mathrm{Fe}^{2+}\right)$, and sulfide (HS-), continue to accumulate under the anoxic condition (Canfield, Thamdrup \& Hansen, 1993; Middelburg \& Levin, 2009). Thus, a buildup of the reduced compounds leads to increased SOC whenever the bottom DO levels recover. It is, therefore, important to quantitatively evaluate the impacts of both aerobic and anaerobic respiratory processes in the sediment over a wide range of DO conditions from normoxia to anoxia.

SOC can be divided into two components: biological oxygen consumption (BOC) and chemical oxygen consumption (COC). The former reflects aerobic respiration by sediment microbes, while the latter reflects the chemical reactions between reduced compounds and oxygen. Although the relative importance of BOC within SOC has long been suggested (Jørgensen, 1977), methods used to determine the individual contributions of sediment BOC and COC have yet to be fully 
developed. Several previous oceanographic and limnological studies have attempted to explicitly determine $\mathrm{COC}$ and BOC by comparing SOC rates of fresh and fixed sediment core samples (Seiki et al., 1994; Zimmerman \& Benner, 1994). However, it often resulted in overestimation of sediment $\mathrm{COC}$ due to $\mathrm{pH}$ change or the increased penetration depth of oxygen induced by fixatives (Sweerts et al., 1991; Zimmerman \& Benner, 1994).

In our previous studies, the tetrazolium dye reduction assay for non-destructed sediment samples was applied to estimate SOC in a seasonally hypoxic inner bay (Omura Bay, Japan). We assumed two electrons were used to reduce one mole of 2-(4-iodophenyl)-3-(4-nitrophenyl)-5phenyl-2H-tetrazolium chloride (INT), which is equivalent to the reduction of $1 / 2 \mathrm{O}_{2}$ (Wada et al., 2012). We further demonstrated that the potential COC (pCOC) from formalin-fixed sediment samples comprised on average $72 \%$ of the potential whole oxygen consumption (pWOC) (Mori et al., 2015). In some cases, a greater pCOC than pWOC was found, suggesting an effect of fixatives. Another intriguing finding was the apparent increase in potential BOC (pBOC) during severe hypoxia. As the $\mathrm{pBOC}$ was estimated by subtracting $\mathrm{pCOC}$ from $\mathrm{pWOC}$, the actual $\mathrm{pBOC}$ may be greater than that estimated, due to the enhancement of pCOC via formalin fixation. Given the fact that aerobic bacterial activity is suppressed under oxygen depletion in situ, it is likely facultative anaerobes are responsible for the increased $\mathrm{pBOC}$. These results raised questions regarding the activity and composition of the microbial (bacterial) community responsible for the SOC in the bay.

However, there are some constraints to be addressed in the methodology used before exploring ecologically relevant questions any further, as the SOC results inferred from the assay were far below those obtained with other direct methods. One possible reason is the development of an oxygen boundary layer over the sediment surface during the incubation assay (Inoue \& Nakamura, 
93

2009). Another possible reason is the potential toxicity of INT (Martínez-García et al., 2009). Although a good positive correlation between INT reduction and oxygen consumption of aerobically incubated sediment samples has been reported (Trevors, 1984), extensive comparisons between the data obtained with this method and those from direct measurement of SOC must be conducted to quantitatively address the microbial respiratory processes in the sediment.

$$
\text { Linking SOC dynamics with microbial community composition is key to understanding the }
$$
biogeochemical processes in sediment ecosystems. It was recently suggested that members of the chemolithoautotrophic sulfur oxidizing bacteria make a substantial contribution to SOC in seasonally hypoxic sediment environments (Seitaj et al., 2017). A facultative chemolithoautotrophic Woeseiaceae, a predominant and core member of microbial communities in sediments worldwide, possesses cytochrome c oxidases for aerobic respiration and is therefore likely to make a significant contribution to SOC dynamics (Mußmann et al., 2017). Furthermore, members of chemolithotrophic cable bacteria have also been shown to make a large contribution to the total annual oxygen uptake in seasonally sulfidic sediment (Seitaj et al., 2017). In our previous studies of Omura Bay, we found a shift in sediment bacterial community structure that occurred as DO levels in the bottom water changed (Mori et al., 2018a,b). Members of the aerobic Gammaproteobacterial group decreased as oxygen became depleted, while members of the sulfatereducing Deltaproteobacterial group increased and became predominant. The predominance of sulfate-reducing bacteria enhances the accumulation of hydrogen sulfide $\left(\mathrm{H}_{2} \mathrm{~S}\right)$ in sediment, which migrates upward to reach the overlying water and consumes oxygen through abiotic and/or biotic processes. However, further details of the bacterial contribution to SOC dynamics are yet to be determined. 
115 The primary objective of this study was to reveal the dynamics of potential oxygen consumption 116 at the sediment surface of Omura Bay and to uncover the bacterial community composition that 117 contributed to the pBOC. First, we compared the extent of INT reduction with that of oxygen 118 consumption determined using direct measurement of DO in sediment slurry. Based on the 119 correlation between them, relative contribution of $\mathrm{pBOC}$ and $\mathrm{pCOC}$ to $\mathrm{pWOC}$ (SOC) was inferred 120 for a central site of the bay during two consecutive years (2012-2013). We further assessed 121 changes in the bacterial 16S rRNA gene sequences during incubation for the INT reduction assay. 
124 Materials and Methods

125 Study Site Description and Sampling Procedure

126 Omura Bay is in Nagasaki Prefecture, western Kyushu, Japan. It comprises steep cliffs at the margins and a large, flat seafloor at a water depth of 15-20 m (Kato et al., 2003). The bay is extremely enclosed, is connected to the open sea (East China Sea) by just two narrow channels. Cold and dense oxygenated water flows into the bottom of the bay in winter through these channels (Nogami et al., 2000; Takahashi et al., 2009). In early summer, warmer and less dense water intrudes into the middle layer of the bay, leaving the bottom water below the depth of intrusion stagnant, consequently leading to hypoxia in the central region of the bay (Nogami et al., 2000; Takahashi et al., 2009). In autumn, usually by October, this hypoxic water mass disappears as the vertical convection becomes activated by cooling of the sea surface (Suzaki, Miyake \& Nakata, 2013).

Oceanographic monitoring and sediment core sampling were conducted at a central site in Omura Bay (Station 21; 20 m water depth; 3255.390’N, 12951.350’E; see Mori et al., 2018b). During the summer months of 2012 and 2013 (Table 1), sediment samples were hand-collected with an acrylic pipe (length $31 \mathrm{~cm}$, inner diameter 26-mm) whilst scuba diving. Surface areas with visible bioturbation were not included in the samples. Temperature, salinity, DO, and chlorophylla fluorescence in the water column at the sampling site were measured using a multi-parameter monitoring device (AAQ, JFE-Advantec Co, Kobe, Japan). All of the sediment core samples were stored at an in situ temperature and carefully transported to the laboratory within $3 \mathrm{~h}$ of collection, avoiding direct exposure to sunlight and other physical disturbances. For the DNA analysis, the top layers $(0-5 \mathrm{~mm})$ of three sediment cores were pooled and stored at $-20^{\circ} \mathrm{C}$ until DNA extraction was performed. 
147

148

149

150

151

152

153

154

155

156

157

158

159

160

161

162

163

164

165

166

167

168

169

For a series of experiment to compare INT reduction and oxygen consumption (slurry experiments, see below), additional cores were collected using a gravity core sampler (Ashura, Rigosha Co. Ltd, Japan), equipped with three polycarbonate tubes (length $57 \mathrm{~cm}$, inner diameter $82 \mathrm{~mm}$ ), in August 2017 and 2020. Each sediment core was sliced at a depth $0-5 \mathrm{~cm}$, the sliced sediments were pooled on board the training ship, Kakuyo-Maru, and then stored at $-80^{\circ} \mathrm{C}$ until further processing.

For the time-course experiments, another set of additional sediment cores were collected from the same sampling site of Omura Bay (St. 21) using an acrylic tube (length $31 \mathrm{~cm}$, inner diameter $26 \mathrm{~mm}$ ), whilst scuba diving on August 7 and September 8, 2014.

\section{Comparison between The Extent of a Tetrazolium Dye Reduction and Oxygen Consumption} of The Sediment Samples (slurry experiments)

The sediment samples collected in 2017 and 2020 were used to determine the relationship between INT reduction and oxygen consumption in sediment. The tetrazolium dye reduction assay was based on the reduction of INT by the dehydrogenase activity of sediment microorganisms and reduced compounds such as sulfide in the sediment (Wada et al., 2012). To reveal the quantitative relationship between INT reduction and oxygen consumption by the sediment samples, we performed a series of incubation experiments using sediment slurries. A freshly thawed slurry sample was prepared by suspending sediment (approximately $3 \mathrm{~g}$ ) into $1 \mathrm{~L}$ of aerated and filtersterilized $(0.22 \mu \mathrm{m})$ artificial seawater (Tetra Marine Salt Pro, Tetra Japan, Tokyo, Japan). The sediment slurry was further divided into two, one was incubated at $20^{\circ} \mathrm{C}$ for $20 \mathrm{~h}$ without aeration prior to the assay, and the other was directly used for the assay without such a pre-incubation. Afterward, the samples were stored at room temperature and aeration was provided for different 
170 periods of time, for up to $48 \mathrm{~h}$, to adjust the amount of reduced compounds in the samples. The

171 sediment slurries were aliquoted into three glass bottles $(100 \mathrm{ml}$ each) to which INT (final

172 concentration $0.01 \%$ ) was added. Each of these samples was gently mixed with a stirrer for $24 \mathrm{~h}$

173 at $26^{\circ} \mathrm{C}$ under dark conditions. Following this incubation, the slurries were centrifuged at $1,610 \times$

$174 \mathrm{~g}$ for $10 \mathrm{~min}$, and the supernatants were filtered through a cellulose acetate membrane filter (pore

175 size $0.22 \mu \mathrm{m}$, Advantec, A020A025A). Both the filter and the pellet (sediment) were stored at

176 below $-20^{\circ} \mathrm{C}$ until analysis. The reduced form of INT (INT-formazan [INTF]) was extracted from

177 the filters and sediments according to the method of Wada et al. (2012). The INTF concentration

178 in the extract was calculated by applying a standard curve with five different known concentrations

179 (ranging from 0.5 to $50 \mu \mathrm{M}$ ) of pure INTF (Sigma-Aldrich, USA), dissolved in isopropanol for the

180 filter and methanol for the sediment. We used the following equation to calculate the whole INT

181 reduction rate:

$182 \quad$ INTF $\mu$ mol g ${ }^{-1}$ day $^{-1}=\frac{A+B}{D_{w}} \times \frac{1}{T}$

183

184

185

186

187

188

189

190

191

192

where $A$ and $B$ are the amounts of INTF extracted from the filter and the sediment, respectively; $D_{w}$ is the dry weight of the sediment used for the extraction of INTF; and $T$ is the time of incubation.

Actual oxygen consumption by the sediment slurries was measured directly using an optode sensor (FireSting O2 fiber-optic oxygen meter; Pyro Sciences, Aachen, Germany) in parallel with the whole INT reduction measurement. Oxygen concentrations in the glass bottles were recorded every $30 \mathrm{~s}$. The sediment slurry was incubated in duplicate under the same conditions as described for the assay of the sediment cores $\left(26^{\circ} \mathrm{C}\right.$, under dark conditions, $\left.24 \mathrm{~h}\right)$. Ultra-pure MQ water $(10 \mathrm{~mL})$ was added to each of the slurry samples instead of the aqueous INT solution. Oxygen 
193

194

195

196

197

198

199

200

201

202

203

204

205

206

207

208

209

210

211

212

213

214

\section{.}

concentrations in the bottles were recorded for $24 \mathrm{~h}$ after the initiation of measurement. To estimate the oxygen consumption rate, a generalized additive model (GAM) was fitted to the changes in DO during the incubation period (Eq. 2).

$$
\mathrm{y}=f(x)+b
$$

198

Here, $\mathrm{y}$ is the DO, $\mathrm{x}$ is time, $\mathrm{f}(\mathrm{x})$ is the smoothing function, and $\mathrm{b}$ is the intercept.

Instantaneous consumption rates were determined by taking the first-order derivative of the

fitted GAM. These rates were integrated to obtain the total consumption rate during the experiment. The GAM was fitted using the mgcv package (Wood, 2003) in R (version 3.5.0), assuming a Gaussian distribution, an identity link function, and a thin plate spline as the smoothing function. The upper limit for the degrees of freedom of $f(x)$ was 10 .

For the sediment fixed with formaldehyde, we also measured the rate of chemical oxygen consumption (COC) and the non-biological (chemical) reduction of INT. Five samples of non-preincubated or pre-incubated sediment slurries $\left(20^{\circ} \mathrm{C}\right.$ for $20 \mathrm{~h}$ without aeration) were prepared for the assay. Afterward, the samples were fixed by adding $10 \mathrm{~mL}$ formalin (formaldehyde: $3.7 \% \mathrm{w} / \mathrm{v}$ final concentration). After $15 \mathrm{~min}$, INT (final concentration $0.01 \% \mathrm{w} / \mathrm{v}$ ) and ultra-pure MQ water were added to the fixed slurries. They were stored at $26^{\circ} \mathrm{C}$ under dark conditions for $24 \mathrm{~h}$. The COC of the slurry samples was determined in duplicate using the optode, as described above. INTF was extracted from the slurries in triplicate, and chemical INT reduction rate was determined in the same way as described for whole INT reduction. In an additional experiment, sediment slurries (non-pre-incubation sample) were supplied with sterile air for up to $24 \mathrm{~h}$ before formalin fixation to adjust the concentration of reduced compounds in the sediment. A generalized linear model 
215 (GLMs) assuming a gamma distribution with a log-link function was applied to analyze the entire

216 set of data (Eq. 3).

217

$$
\begin{aligned}
& y \sim \operatorname{Gamma}(\mu, \sigma) \\
& \log (\mu)=b_{0}+b_{1} x
\end{aligned}
$$

218 The model coefficients are $b_{0}$ and $b_{1}, \mu$ is the expected value on the log-link scale, $x$ is the INTF, $219 \sigma$ is the shape parameter, and $y$ are the observations (dissolved oxygen consumption rate). 
238 Advantec, A020A025A). The filters were stored below $-20^{\circ} \mathrm{C}$ until analysis. The sediment cores 239 were vertically extruded and sliced into horizontal sections of $0-5 \mathrm{~mm}$ depth. The sediment slices 240 were stored at less than $-20^{\circ} \mathrm{C}$. INTF extraction was performed as described by Wada et al. (2012). 241 The INTF concentration in the extract was calculated by applying a standard curve derived from 242 five different concentrations (ranging from 0.5 to $50 \mu \mathrm{M}$ ) of pure INTF (Sigma-Aldrich), dissolved 243 in isopropanol and methanol for the water and sediment samples, respectively. The concentrations extraction. above. 


\section{Principal Component Analysis (PCA) of The Environmental Parameters and Correlation} Analysis of The pWOC, pBOC, and pCOC Activities

Previously published data for the in situ environmental parameters (temperature, salinity, DO, and chlorophyll-a fluorescence in the bottom water and the quantities of sediment organic carbon, and nitrogen) (Mori et al., 2015, 2018b) were compiled for the PCA. The PCA allowed us to reduce the multicollinearity inherent in the environmental variables, and the first three principal components (PCs) were used as covariates for the ensuing GLMs to examine correlations between with pWOC, pCOC, and pBOC. (Eq. 4).

$$
\begin{gathered}
y \sim \operatorname{Gamma}(\mu, \sigma) \\
\log (\mu)=b_{0}+b_{1} \mathrm{PC} 1+b_{2} \mathrm{PC} 2+b_{3} \mathrm{PC} 3
\end{gathered}
$$

The model coefficients are $b_{0}, b_{1}, b_{2}$, and $b_{3}, \mu$ is the expected value on the log-link scale, $\sigma$ is the shape parameter, and $y$ are the observations (pWOC, $\mathrm{pBOC}$, and $\mathrm{pCOC}$ ).

PCA and the subsequent GLM analyses were performed using the prcomp and glm functions in R (version 3.5.0). In the visualization steps, the "factoextra" (Kassambara \& Mundt, 2020), “broom” (Robinson, Hayes \& Couch, 2020), and “ggplot2” (Wickham, 2016) packages were used.

\section{Illumina MiSeq 16S rRNA Gene Amplicon Sequencing}

Microbial genomic DNA in the sediment samples was extracted using an ISOIL DNA extraction kit (Nippon Gene, Tokyo, Japan), according to the manufacturer's instructions. A total of ten genomic samples obtained from the surface sediment layer $(0-5 \mathrm{~mm}$ depth) at the five sampling times in 2012, collected before and after incubation for the INT reduction measurement, were amplified for Illumina MiSeq 16S rRNA gene amplicon sequencing. Primers specific for the V3-V4 regions of the 16S rRNA gene, 341F and 805R (Herlemann et al., 2011), were used. The PCR was conducted in a $25-\mu \mathrm{L}$ reaction mixture using a PCR buffer, $5 \mu$ forward primer $(1 \mu \mathrm{M})$, 
283

284

285

286

287

288

289

290

291

292

293

294

295

296

297

298

299

300

301

302

303

304

305

$5 \mu \mathrm{l}$ reverse primer $(1 \mu \mathrm{M}), 12.5 \mu \mathrm{l} 2 \mathrm{X}$ Kapa HiFi HotStart ReadyMix (Kapa Biosystems, Boston, MA, USA), and $10 \mathrm{ng}$ of the extracted DNA. Then, 27 cycles of PCR with an initial step of $95^{\circ} \mathrm{C}$ for $3 \mathrm{~min}$ were run, followed by $95^{\circ} \mathrm{C}$ for $30 \mathrm{~s}, 55^{\circ} \mathrm{C}$ for $30 \mathrm{~s}, 72^{\circ} \mathrm{C}$ for $30 \mathrm{~s}$, and finally, $72^{\circ} \mathrm{C}$ for 5 min. The size of the PCR products was verified by agarose gel electrophoresis, and the PCR products were further purified with Agencourt AMPure XP (Beckman Coulter, Indianapolis, USA), according to the manufacturer's instructions. A second PCR reaction was performed on the purified PCR products $(2.5 \mu \mathrm{l})$ to index each of the samples. Two indexing primers (Illumina Nextera XT 72 indexing primers, Illumina, California, USA) were used per sample. The second PCR was carried out in a $25-\mu \mathrm{L}$ reaction mixture using a PCR buffer, $5 \mu$ forward index primer $(1 \mu \mathrm{M}), 5 \mu \mathrm{l}$ reverse index primer $(1 \mu \mathrm{M}), 12.5 \mu \mathrm{l}$ 2X Kapa HiFi HotStart ReadyMix (Kapa Biosystems), and $2.5 \mu \mathrm{l}$ of the first PCR products. The second PCR products were then also purified (Agencourt AMPure XP; Beckman Coulter). Following purification, all samples were sent to the Bioengineering Lab. Co., Ltd. for massively parallel 300-bp paired-end sequencing, which was performed on an Illumina MiSeq analyzer. Processing and quality control of the reads was performed using R. For raw sequence data, the adapter sequences were trimmed using the "quasR" package (Gaidatzis et al., 2015). Following quality control processes, inclusive of chimera removal, the removeBimeraDenovo, filterAndTrim and dada function in the "DADA2" package version 1.6 (Callahan et al., 2016) were used, with default settings. Finally, the amplicon sequence variants (ASVs) (Callahan, McMurdie \& Holmes, 2017) were classified from kingdom to genus level using the SILVA 132 SSU Ref NR 99 database (Quast et al., 2013), resulting in the construction of an ASV table with read counts for the ASVs in all samples. In the visualization step, the "phyloseq" (McMurdie \& Holmes, 2013) and "ggplot2" packages were used to create stacked bar and plots. To delineate a hierarchical clustering plot, the ASV table was standardized 
306 based on coverage-based rarefaction (Chao \& Jost, 2012). Thereafter, the distance matrix was 307 calculated based on the Bray-Curtis dissimilarity, and clusters were calculated using Ward's 308 method. The "vegan" package (Oksanen et al., 2019) and hclust function were used to calculate 309 the dissimilarity and clusters.

310 All associated raw data can be found at the DDBJ Sequence Read Archive under accession 311 numbers DRA008748 (DRX177081-DRX177090).

312 


\section{Results and Discussion}

\section{Comparison between The Extent of Tetrazolium Dye Reduction and Oxygen Consumption} of The Sediment Samples (slurry experiments)

The whole INT reduction rates in the sediment slurries ranged from 7.4 to $28.5 \mu$ mol INTF g-1 day $^{-1}$, while actual oxygen consumption rates ranged from 44.3 to $390.5 \mu$ mol O$~ \mathrm{~g}^{-1}$ day $^{-1}$ ( $\mathrm{n}=$ 16). The chemical INT reduction ranged from 0.6 to $25.6 \mu \mathrm{mol}$ INTF $\mathrm{g}^{-1}$ day $^{-1}$, while oxygen consumption from the same samples ranged from 38.8 to $147.1 \mu \mathrm{mol} \mathrm{O} \mathrm{g}^{-1}$ day $^{-1}(\mathrm{n}=25)$ (Fig. 1, Supplemental Table S1). We found a significant relationship between INT reduction rate and oxygen consumption rate in Omura Bay sediment (Eq. 2, $\mathrm{P}<0.0001$, Fig. 1). If we estimate the values of the pWOC based on the GLM model, it ranged from 45.9 to $91.1 \mu \mathrm{mol} \mathrm{O} \mathrm{g}{ }^{-1} \mathrm{day}^{-1}$, which can be converted to areal unit using density of sediment and the area of sediment core (45.3 to 56.1 mmol O $\mathrm{m}^{-2}$ day $\left.^{-1}\right)$. These $\mathrm{pWOC}$ values were comparable with the WOCs reported for the basins of other coastal areas, such as the East China Sea (3.6-17.6 $\mathrm{mmol} \mathrm{O}_{2} \mathrm{~m}^{-2} \mathrm{day}^{-1}$, Song et al, (2016)), the northern Gulf of Mexico (0.82-56.4 $\mathrm{mmol} \mathrm{O}_{2} \mathrm{~m}^{-2}$ day-1, Rowe, Kaegi \& Morse, (2002)), and the Seto Inland Sea (3.6-17.6 mmol $\mathrm{O}_{2} \mathrm{~m}^{-2}$ day $^{-1}$, Nakamura, (2003)). Therefore, the INT reduction method should work reasonably well to estimate SOC in coastal environments.

The extent of INT reduction has been proven to be an reliable proxy to estimate the oxygen consumption rate of planktonic microorganisms (Martínez-García et al., 2009; Villegas-Mendoza, Cajal-Medrano \& Maske, 2019; García-Martín et al., 2019), despite the inherent toxicity of INT (Martínez-García et al., 2009; Villegas-Mendoza, Cajal-Medrano \& Maske, 2015). Previous studies also showed a positive correlation between INT reduction and oxygen consumption for estuary sediments (Trevors, 1984) and terrestrial soils (Trevors, Mayfield \& Inniss, 1982). However, none of them have addressed whole INT reduction and chemical INT reduction 
336 separately or determined their correlation coefficients with SOC. Thus, to the best of our 337 knowledge, the present results are the first to demonstrate the relationship between INT reduction and oxygen consumption in marine sediment with a significant correlation coefficient that would allow us to estimate potential SOC based on the INT reduction rates.

\section{Time-course Experiments}

We found that the quantity of INTF increased consistently for up to $24 \mathrm{~h}$ without appreciable decline in selected sediment core samples (Supplemental Figure S1). This was in stark contrast to what had been reported to the planktonic samples. Martínez-García et al. (2009) and others (Villegas-Mendoza, Cajal-Medrano \& Maske, 2015; García-Martín et al., 2019) demonstrated that prolonged incubation times can cause an underestimation of the INT reduction rate due to breakage of microbial cells that accumulated INTF crystals inside their cellular membrane. The seemingly discrepancy between sediment and planktonic samples may be attributable to better extraction efficiency of INTF from sediment samples. Regardless of cell breakage, majority of INTF crystals formed in sediment microbial cells were likely to be retained on the sediment surface and were directly extracted from the sediment slices with methanol. In contrast, INTF crystals formed in planktonic samples could be lost if the size of INTF grain was smaller than that of pore size of the filters. Furthermore, the time for INT in overlying water to reach and exhibit toxicity on microbial cells in the sediment may be delayed due to a slow diffusion of INT across the boundary layer that would develop over the sediment surface under the static condition of the assay. 
Based on the GLM model obtained with the slurry experiments, the potential SOC in the intact core samples ranged from 45.3 to $56.1 \mathrm{mmol} \mathrm{O}_{2} \mathrm{~m}^{-2}$ day-1. However, as most of the whole INT reduction in the core samples turned out to be far below the minimum value in the slurry experiments (Fig. 1, Supplemental Table S1), we decided not to describe and discuss the results any further based on the conversion the INT reduction rates into SOC, but to use whole, chemical and biological INT reduction as proxies for potential WOC $\left(\mathrm{pWOC}_{\mathrm{INT}}\right), \mathrm{COC}\left(\mathrm{pCOC}_{\mathrm{INT}}\right)$, and BOC $\left(\mathrm{pBOC}_{\mathrm{INT}}\right)$, respectively.

Figure 2 showed the three components of SOC at the central part of Omura Bay during early summer to late autumn in 2012 and 2013 (Fig. 2 A-C, Table 1) together with those in 2011 that had been already published (Mori et al., 2015) in order to make the downstream statistical analysis more robust. Both $\mathrm{pWOC}$ INT and $\mathrm{pCOC}_{\mathrm{INT}}$ tended to be greater in August and September than in other sampling months. According to the criteria used by Wright, Konwar \& Hallam. (2012), we defined hypoxic conditions as $<90 \mu \mathrm{M} \mathrm{O}_{2}$, and divided the DO level into four categories: Oxic ( $\left.>90 \mu \mathrm{M} \mathrm{O}_{2}\right)$, dysoxic $\left(90-20 \mu \mathrm{M} \mathrm{O}_{2}\right)$, suboxic $\left(20-1 \mu \mathrm{M} \mathrm{O}_{2}\right)$, and anoxic $\left(<1 \mu \mathrm{M} \mathrm{O} \mathrm{O}_{2}\right)$. The potential activity of SOC was highest under suboxic or anoxic conditions in the bottom water. As the highest $\mathrm{pBOC}_{\mathrm{INT}}$ in 2012 and $2013\left(2.82 \mu \mathrm{mol} \mathrm{INTF} \mathrm{g}^{-1}\right.$ day $^{-1}$ in 2012 and $4.16 \mu \mathrm{mol}$ INTF $\mathrm{g}^{-1}$ day $^{-1}$ in 2013) coincided with the timing of the highest bacterial count in each year $\left(1.7 \times 10^{11}\right.$ cells/g sediment in 2012 and $3.2 \times 10^{10}$ cells/g sediment in 2013, Table 1), it was likely that the increases in facultative anaerobes or aerobes contributed to the surge of the $\mathrm{pBOC}_{\mathrm{INT}}$. In five out of 20 cases, $\mathrm{pCOC}_{\mathrm{INT}}$ exceeded $\mathrm{pWOC}_{\mathrm{INT}}$, and $\mathrm{pBOC}_{\mathrm{INT}}$ showed negative values (Table1, Fig. 2A-C). This may be partly explained by the effect of formalin addition on SOC as described above, which lead to an enhancement of COC in the sediment. 
In order to identify the environmental driver(s) for the variation of potential SOC, we first conducted PCA for all the environmental variables examined (DO concentration, temperature, and salinity in the bottom water within $0.5 \mathrm{~m}$ above the seafloor; and TOC and TON contents in the sediment), during 2011 through 2013 (Table 2, Fig. 3A) and tested the correlation between the obtained principal components (PCs) and the potential SOC (Table 3). It was indicated that the first three PCs explained $93 \%$ of the variability of the variables (Table 2). The results of PC1 suggest that TOC as well as TON in the sediment increased in the opposite directions from DO and temperature, reflecting a tendency of organic matter preservation in the sediment under hypoxia. On the other hand, the results of PC2 suggest that temperature increased in the opposite directions from salinity and $\mathrm{DO}$, reflecting a temporal variation of those variables in hypoxic water mass overlying the sampling location. GLM analysis showed that only PC2 had a significant effect on $\mathrm{pWOC}_{\mathrm{INT}}$ and $\mathrm{pCOC}_{\mathrm{INT}}$ (Table 3, Fig. 3B, D). These results strongly suggest that temperature as well as DO in the bottom water acts as environmental drivers that control the potential SOC.

\section{Bacterial community composition and Its Response to Re-oxygenation}

A total of 2,546 unique ASVs were identified in the surface sediment from the center of Omura Bay in 2012. The dominant taxa in the bacterial communities were affiliated with the Deltaproteobacteria, Gammaproteobacteria, and Bacteroidia (Fig. 4). Within the Deltaproteobacteria class, the family groups of Desulfobacteraceae (major genera Sva0081 sediment group and Desulfobacter) and Desulfobulbaceae (major genera Desulfopila and MSBL7), which belong to the dominant order Desulfobacterales, were predominant (Supplemental Figure S2). In contrast, family groups in Woeseiaceae (major genus Woeseia), Halieaceae (major genus Halioglobus), and Thiotrichaceae (which were not assigned to genus level) were 
403

404

405

406

407

408

409

410

411

412

413

414

415

416

417

418

predominant in the Gammaproteobacterial class (Supplemental Figure S3). Among the bacterial groups, Woeseiaceae was recently reported to be a cosmopolitan and abundant core member of the bacterial communities in marine sediments globally (Dyksma et al., 2016; Mußmann et al., 2017). These bacterial groups are frequently reported to be present in marine sediment surfaces (Kawahara et al., 2009; Zinger et al., 2011; Dyksma et al., 2016; Jochum et al., 2017).Therefore, the bacterial community composition in the surface sediment of Omura Bay demonstrated the ubiquity of the organisms (e.g., Desulfobacteraceae and Woeseiaceae) found in marine sediments. According to our previous study (Mori et al., 2018a,b), temporal shifts in the bacterial community in the surface sediment of Omura Bay were characterized by decreases in the relative abundance of the ASVs affiliated with Gammaproteobacteria toward less oxic conditions; conversely, those affiliated with Deltaproteobacteria exhibited the opposite results. The present results were essentially consistent with this trend, although there was a peak in the relative abundance of Deltaproteobacteria under the oxic condition in September 2012 (Table 1). A strong typhoon, Sanba, had passed near Omura Bay on the day before we collected the sediment cores in September 2012. Due to the strong wind ( $>12 \mathrm{~m} / \mathrm{sec}$ on average) of the typhoon, water column of entire bay must have been mixed rigorously and oxygenated the bottom water. This mixing event is likely to be largely responsible for the contradiction between bottom water oxygen levels and the peak in Deltaproteobacteria. In contrast to a large fluctuation of DO in the water column under the typhoon, relative abundance of Deltaproteobacteria in the sediment seemed less affected.

Following the incubation (24h) of sediment core samples, more than $90 \%$ of the ASVs (comprising 90.2\%-96.6\% of the total reads) did not substantially change their relative abundance $(<0.1 \%$ of the abundance). Consistent with this notion, the ASVs were tightly clustered by sampling months (Fig. 5). However, it was found that several ASVs exhibited large increases or 
426 decreases during the incubation period. The majority of the increased ASVs belonged to the 427 Arcobacteraceae, Fusobacteriaceae and Halieaceae family groups, while those of the decreased ASVs were affiliated with the Flavobacteriaceae, Saprospiraceae and Spirochaetaceae family groups (Fig. 6). The relative abundance of the Arcobacteraceae family group increased from $<1 \%$ to $12.9 \%$ within $24 \mathrm{~h}$ in the sediment cores that were retrieved under anoxic bottom water conditions (August 24, 2012) (Supplemental Table S2). It was interesting to note that the increase in the relative abundance of Arcobacter ASVs coincided with the highest pBOC (Fig. 2). The Arcobacter comprise a group of physiologically diverse bacteria that exhibit anaerobic dissimilatory manganese reduction (Vandieken et al., 2012) or aerobic sulfide oxidation (Wirsen et al., 2002; Sievert et al., 2007). Given that these bacterial groups have been found in marine sediments under suboxic conditions and were reportedly engaged in the sulfur cycles (Wirsen et al., 2002; Sievert et al., 2007), the surge in $\mathrm{pBOC}_{\mathrm{INT}}$ in August 2012 could be ascribed to the aerobic oxidation of reduced sulfur compounds by Arcobacter. Consistent with this interpretation, a recent report on the metatranscriptomics of anoxic marine sediment revealed Arcobacter was highly responsive to oxygenation event and upregulated expression level of the genes encoding for respiratory proteins (Broman et al., 2017). Therefore, it is very likely that the anoxic sediment of Omura Bay harbored an Arcobacter population capable of rapidly growing in response to the replenishment of DO. Besides Arcobacter, it is reasonable to assume the other bacterial groups whose relative abundance increased notably during the incubation period, such as Fusobacteriaceae and Halieaceae (Fig. 6), also contributed to the $\mathrm{pBOC}_{\mathrm{INT}}$.

On the other hand, it was difficult to associate the dominant bacterial groups with potential respiratory activities. Even though a majority of the predominant components of the bacterial community, such as the Woeseiaceae group, is likely to play a role in sediment metabolism, the 
449 present results provided no further insights to support this inference. One possibility for the contribution of dominant groups to the SOC is that highly abundant anaerobic sulfate reducing bacteria might have affected the seasonal dynamics of $\mathrm{pBOC}$ via their aerobic respiration. The sulfate reducing bacteria inhabiting the sediment surface generally possess abilities to cope with high oxygen stress, and some of those are capable of aerobic respiration (Cypionka, 2000; Brioukhanov, Pieulle \& Dolla, 2010; Zhou et al., 2011), which possibly contributes to pBOC $\mathrm{INT}$ during the oxygenation experiment. Indeed, the maximum $\mathrm{pBOC}_{\mathrm{INT}}$ observed in August 2012 was the timing when cells abundance was peaked and sulfate reducing Deltaproteobacteria, including the groups capable of aerobic respiration such as Desulfobacter (Dannenberg et al., 1992), was highly abundant in the surface sediment (Fig. 2B, Table 1, Supplemental Figure S2). It is not clear whether electrogenic sulfur oxidation by cable bacteria plays roles in Omura Bay, as we did not detect the cable bacteria genus (i.e., Candidatus Electrothrix). It will be worth investigating its presence using other methods, such as fluorescent in situ hybridization, in any future studies.

\section{Conclusion}

We quantitively demonstrated a significant relationship between INT reduction and potential SOC in Omura Bay. Based on the relationship, it was revealed that not only $\mathrm{pCOC}_{\mathrm{INT}}$ but also $\mathrm{pBOC}_{\mathrm{INT}}$ increased during the hypoxic period of the bay, highlighting much greater contribution of $\mathrm{pBOC}$ to the $\mathrm{pWOC}$ in hypoxic sediment than previously thought. We further demonstrated Arcobacter could play vital roles in pBOC during hypoxia. This bacterial group may rapidly grow at the sediment surface in response to the episodic dissolved oxygen supply to otherwise hypoxic bottom. Sulfate reducing bacteria were dominant in the sediment surface under anoxic conditions and possibly contributed to the $\mathrm{pBOC}$ via aerobic respiration when dissolved oxygen was 
472 temporarily supplied. Clearly, more detailed studies are necessary to clarify the contribution of 473 phylogenetically diverse sedimentary bacteria to the seasonal dynamics of coastal SOC.

474 
475

\section{References}

Brioukhanov A, Pieulle L, Dolla A. 2010. Antioxidative defense systems of anaerobic sulfate-reducing microorganisms. Current Research, Technology and Education Topics in Applied and Microbial Biotechnology:148-159.

Broman E, Sachpazidou V, Pinhassi J, Dopson M. 2017. Oxygenation of Hypoxic Coastal Baltic Sea Sediments Impacts on Chemistry, Microbial Community Composition, and Metabolism. Frontiers in Microbiology 8:2453. DOI: 10.3389/fmicb.2017.02453.

Callahan BJ, McMurdie PJ, Holmes SP. 2017. Exact sequence variants should replace operational taxonomic units in marker-gene data analysis. The ISME Journal 11:26392643. DOI: 10.1038/ismej.2017.119.

Callahan BJ, McMurdie PJ, Rosen MJ, Han AW, Johnson AJA, Holmes SP. 2016. DADA2: High-resolution sample inference from Illumina amplicon data. Nature Methods 13:581-583. DOI: 10.1038/nmeth.3869.

Canfield DE, Thamdrup B, Hansen JW. 1993. The anaerobic degradation of organic matter in Danish coastal sediments: Iron reduction, manganese reduction, and sulfate reduction. Geochimica et Cosmochimica Acta 57:3867-3883. DOI: 10.1016/00167037(93)90340-3.

Chao A, Jost L. 2012. Coverage-based rarefaction and extrapolation: Standardizing samples by completeness rather than size. Ecology 93:2533-2547. DOI: 10.1890/11-1952.1.

Cypionka H. 2000. Oxygen respiration by desulfovibrio species. Annual review of microbiology 54:827-48. DOI: 10.1146/annurev.micro.54.1.827. 

compounds and inorganic sulfur compounds coupled to reduction of $\mathrm{O} 2$ or nitrate by sulfate-reducing bacteria. Archives of Microbiology 158:93-99. DOI: 10.1007/BF00245211.

Dyksma S, Bischof K, Fuchs BM, Hoffmann K, Meier D, Meyerdierks A, Pjevac P,

Probandt D, Richter M, Stepanauskas R, Mußmann M. 2016. Ubiquitous

Gammaproteobacteria dominate dark carbon fixation in coastal sediments. The ISME Journal 10:1939-1953. DOI: 10.1038/ismej.2015.257.

Gaidatzis D, Lerch A, Hahne F, Stadler MB. 2015. QuasR: Quantification and annotation of short reads in R. Bioinformatics 31:1130-1132. DOI: 10.1093/bioinformatics/btu781. García-Martín EE, Aranguren-Gassis M, Karl DM, Martínez-García S, Robinson C, Serret P, Teira E. 2019. Validation of the in vivo Iodo-Nitro-Tetrazolium (INT) Salt Reduction Method as a Proxy for Plankton Respiration. Frontiers in Marine Science 6:115. DOI: $10.3389 /$ fmars.2019.00220.

Herlemann DPR, Labrenz M, Jürgens K, Bertilsson S, Waniek JJ, Andersson AF. 2011. Transitions in bacterial communities along the $2000 \mathrm{~km}$ salinity gradient of the Baltic Sea. ISME Journal 5:1571-1579. DOI: 10.1038/ismej.2011.41.

Inoue T, Nakamura Y. 2009. Effects of Hydrodynamic Conditions on Sediment Oxygen Demand: Experimental Study Based on Three Methods. Journal of Environmental Engineering 135:1161-1170. DOI: 10.1061/(ASCE)0733-9372(2009)135:11(1161). Jochum LM, Chen X, Lever MA, Loy A, Jørgensen BB, Schramm A, Kjeldsen KU. 2017. Depth Distribution and Assembly of Sulfate-Reducing Microbial Communities in Marine Sediments of Aarhus Bay. Applied and environmental microbiology 83:1-15. DOI: 10.1128/AEM.01547-17. 
Jørgensen BB. 1977. The Sulfur Cycle of a Coastal Marine Sediment ( Limfjorden ,

Denmark ). Limnology and Oceanography 22:814-832.

Kassambara A, Mundt F. 2020. factoextra: Extract and Visualize the Results of Multivariate Data Analyses. R package version 1.0.7.

Kato M, Tanimura Y, Matsuoka K, Fukusawa H. 2003. Planktonic diatoms from sediment traps in Omura Bay, western Japan with implications for ecological and taphonomic studies of coastal marine environments. Quaternary International 105:25-31. DOI: $10.1016 / \mathrm{S} 1040-6182(02) 00147-7$.

Kawahara N, Shigematsu K, Miyadai T, Kondo R. 2009. Comparison of bacterial communities in fish farm sediments along an organic enrichment gradient. Aquaculture 287:107-113. DOI: 10.1016/j.aquaculture.2008.10.003.

Martínez-García S, Fernández E, Aranguren-Gassis M, Teira E. 2009. In vivo electron transport system activity: a method to estimate respiration in natural marine microbial planktonic communities. Limnology and Oceanography: Methods 7:459-469. DOI: 10.4319/lom.2009.7.459.

McMurdie PJ, Holmes S. 2013. phyloseq: An R Package for Reproducible Interactive Analysis and Graphics of Microbiome Census Data. PLoS ONE 8:e61217. DOI: 10.1371/journal.pone.0061217.

Middelburg JJ, Levin LA. 2009. Coastal hypoxia and sediment biogeochemistry. Biogeosciences 6:1273-1293. DOI: 10.5194/bg-6-1273-2009.

Mori F, Kondo R, Umezawa Y, Matsuoka K, Suzaki H, Nakata H, Wada M. 2015. Dynamics of Sediment Microbial Community Respiration during the Period of Hypoxia. Bulletin on Coastal Oceanography 53:87-95. (In Japanese with English abstract) 
Mori F, Umezawa Y, Kondo R, Wada M. 2018a. Dynamics of Sulfate-Reducing Bacteria Community Structure in Surface Sediment of a Seasonally Hypoxic Enclosed Bay. Microbes and Environments 33:378-384. DOI: 10.1264/jsme2.ME18092.

Mori F, Umezawa Y, Kondo R, Wada M. 2018b. Effects of bottom-water hypoxia on sediment bacterial community composition in a seasonally hypoxic enclosed bay (Omura Bay, West Kyushu, Japan). FEMS Microbiology Ecology 94:fly053. DOI: 10.1093/femsec/fiy053.

Mußmann M, Pjevac P, Krüger K, Dyksma S. 2017. Genomic repertoire of the Woeseiaceae/JTB255, cosmopolitan and abundant core members of microbial communities in marine sediments. ISME Journal 11:1276-1281. DOI: 10.1038/ismej.2016.185.

Nakamura Y. 2003. Sediment oxygen consumption and vertical flux of organic matter in the Seto Inland Sea, Japan. Estuarine, Coastal and Shelf Science 56:213-220. DOI: 10.1016/S0272-7714(02)00158-0.

Nogami M, Matsuno T, Nakamura T, Fukumoto T. 2000. Estimation of Oxygen Consumption Rate Using T-DO Diagram in the Benthic Layer of Ohmura Bay, Kyushu, Japan. Journal of Oceanography 56:319-329. DOI: 10.1023/A:1011107801693.

Oksanen J, Blanchet FG, Friendly M, Kindt R, Legendre P, McGlinn D, Minchin PR, O’Hara RB, Simpson GL, Solymos P, Stevens MHH, Szoecs E, Wagner H. 2019. vegan: Community Ecology Package. R package version 2.5-6.

Quast C, Pruesse E, Yilmaz P, Gerken J, Schweer T, Yarza P, Peplies J, Glöckner FO. 2013. The SILVA ribosomal RNA gene database project: Improved data processing and web-based tools. Nucleic Acids Research 41. DOI: 10.1093/nar/gks1219. 
Rivera ZJQ, Wissel B, Rabalais NN, Justića D. 2010. Effects of biological and physical factors on seasonal oxygen dynamics in a stratified, eutrophic coastal ecosystem. Limnology and Oceanography 55:289-304. DOI: 10.4319/1o.2010.55.1.0289.

Robinson D, Hayes A, Couch S. 2020. broom: Convert Statistical Objects into Tidy Tibbles version 0.7.0 from CRAN.

Rowe G, Kaegi M, Morse J. 2002. Sediment community metabolism associated with continental shelf hypoxia, northern Gulf of Mexico. Estuaries 25:1097-1106.

Seiki T, Izawa H, Date E, Sunahara H. 1994. Sediment oxygen demand in Hiroshima Bay. Water Research 28:385-393.

Seitaj D, Sulu-Gambari F, Burdorf LDW, Romero-Ramirez A, Maire O, Malkin SY, Slomp CP, Meysman FJR. 2017. Sedimentary oxygen dynamics in a seasonally hypoxic basin. Limnology and Oceanography 62:452-473. DOI: 10.1002/1no.10434.

Sievert SM, Wieringa EBA, Wirsen CO, Taylor CD. 2007. Growth and mechanism of filamentous-sulfur formation by Candidatus Arcobacter sulfidicus in opposing oxygensulfide gradients. Environmental Microbiology 9:271-276. DOI: 10.1111/j.14622920.2006.01156.x.

Song G, Liu S, Zhu Z, Zhai W, Zhu C, Zhang J. 2016. Sediment oxygen consumption and benthic organic carbon mineralization on the continental shelves of the East China Sea and the Yellow Sea. Deep-Sea Research Part II: Topical Studies in Oceanography 124:5363. DOI: 10.1016/j.dsr2.2015.04.012.

Suzaki H, Miyake Y, Nakata H. 2013. Change of oceanic conditions leading to the disappearance of hypoxic water in Omura Bay. Bulletin on Coastal Oceanography 51:7989. (In Japanese with English abstract) 
Sweerts J-PR a., Bär-Gilissen M-J, Cornelese A a., Cappenberg TE. 1991. Oxygenconsuming processes at the profundal and littoral sediment-water interface of a small meso1133. DOI: 10.4319/1o.1991.36.6.1124.

Takahashi T, Nakata H, Hirano K, Matsuoka K, Iwataki M, Yamaguchi H, Kasuya T. 2009. Upwelling of oxygen-depleted water (Sumishio) in Omura Bay, Japan. Journal of Oceanography 65:113-120. DOI: 10.1007/s10872-009-0011-2.

Trevors JT. 1984. Electron Transport System Activity and its Relationship to Other Measures of Activity in an Estuarine Sediment. Systematic and Applied Microbiology 5:136-142. DOI: 10.1016/S0723-2020(84)80058-2.

Trevors JT, Mayfield CI, Inniss WE. 1982. Measurement of Electron Transport System (ETS) activity in soil. Microbial Ecology 8:163-168. DOI: 10.1007/BF02010449.

Vandieken V, Pester M, Finke N, Hyun J-H, Friedrich MW, Loy A, Thamdrup B. 2012. Three manganese oxide-rich marine sediments harbor similar communities of acetateoxidizing manganese-reducing bacteria. The ISME journal 6:2078-90. DOI: 10.1038/ismej.2012.41.

Villegas-Mendoza J, Cajal-Medrano R, Maske H. 2015. INT (2-(4-Iodophenyl)-3-(4Nitrophenyl)-5-(Phenyl) Tetrazolium Chloride) Is Toxic to Prokaryote Cells Precluding Its Use with Whole Cells as a Proxy for In Vivo Respiration. Microbial ecology 70:1004-11. DOI: $10.1007 / \mathrm{s} 00248-015-0626-3$.

Villegas-Mendoza J, Cajal-Medrano R, Maske H. 2019. The chemical transformation of the cellular toxin INT (2-(4-iodophenyl)-3-(4-nitrophenyl)-5-(phenyl) tetrazolium chloride) 
610

as an indicator of prior respiratory activity in aquatic bacteria. International Journal of Molecular Sciences 20:1-11. DOI: 10.3390/ijms20030782.

Wada M, Suzuki S, Nara T, Umezawa Y, Shimanaga M, Matsuoka K, Nakata H. 2012. Microbial community respiration and structure of dead zone sediments of Omura Bay, Japan. Journal of Oceanography 68:857-867. DOI: 10.1007/s10872-012-0136-6.

Wickham H. 2016. ggplot2: Elegant Graphics for Data Analysis. New York: SpringerVerlag.

Wirsen CO, Sievert SM, Cavanaugh CM, Molyneaux SJ, Ahmad A, Taylor LT, DeLong EF, Taylor CD. 2002. Characterization of an autotrophic sulfide-oxidizing marine Arcobacter sp. that produces filamentous sulfur. Applied and environmental microbiology 68:316-25. DOI: 10.1128/AEM.68.1.316-325.2002.

Wood SN. 2003. Thin plate regression splines. Journal of the Royal Statistical Society: Series B (Statistical Methodology) 65:95-114. DOI: 10.1111/1467-9868.00374.

Wright JJ, Konwar KM, Hallam SJ. 2012. Microbial ecology of expanding oxygen minimum zones. Nature reviews. Microbiology 10:381-94. DOI: 10.1038/nrmicro2778. Zhou J, He Q, Hemme CL, Mukhopadhyay A, Hillesland K, Zhou A, He Z, Van Nostrand JD, Hazen TC, Stahl DA, Wall JD, Arkin AP. 2011. How sulphate-reducing microorganisms cope with stress: Lessons from systems biology. Nature Reviews Microbiology 9:452-466. DOI: 10.1038/nrmicro2575.

Zimmerman AR, Benner R. 1994. Denitrification, nutrient regenaration and carbon mineralization in sediments of Galveston Bay, Texas, USA. Marine Ecology Progress Series 114:275-288. 
632

633

634

635

636
Zinger L, Amaral-Zettler LA, Fuhrman JA, Horner-Devine MC, Huse SM, Welch DBM, Martiny JBH, Sogin M, Boetius A, Ramette A. 2011. Global patterns of bacterial betadiversity in seafloor and seawater ecosystems. PloS one 6:e24570. DOI: 10.1371/journal.pone.0024570. 
Figure 1

INTF formation rate $\left(\mu \mathrm{mol} \mathrm{g}{ }^{-1}\right.$ day $^{-1}$ ) vs. oxygen consumption rate $\left(\mu \mathrm{mol} \mathrm{g} \mathrm{g}^{-1}\right.$ day $\left.^{-1}\right)$ for whole sediment oxygen consumption (WOC) and chemical oxygen consumption (COC).

The generalized linear model (GLM) used a gamma distribution with a log-link function (Eq. 3, $P<0.0001)$. The fitted lines represent the mean response, and the shaded area indicates the $95 \%$ quantiles of the marginal distribution.

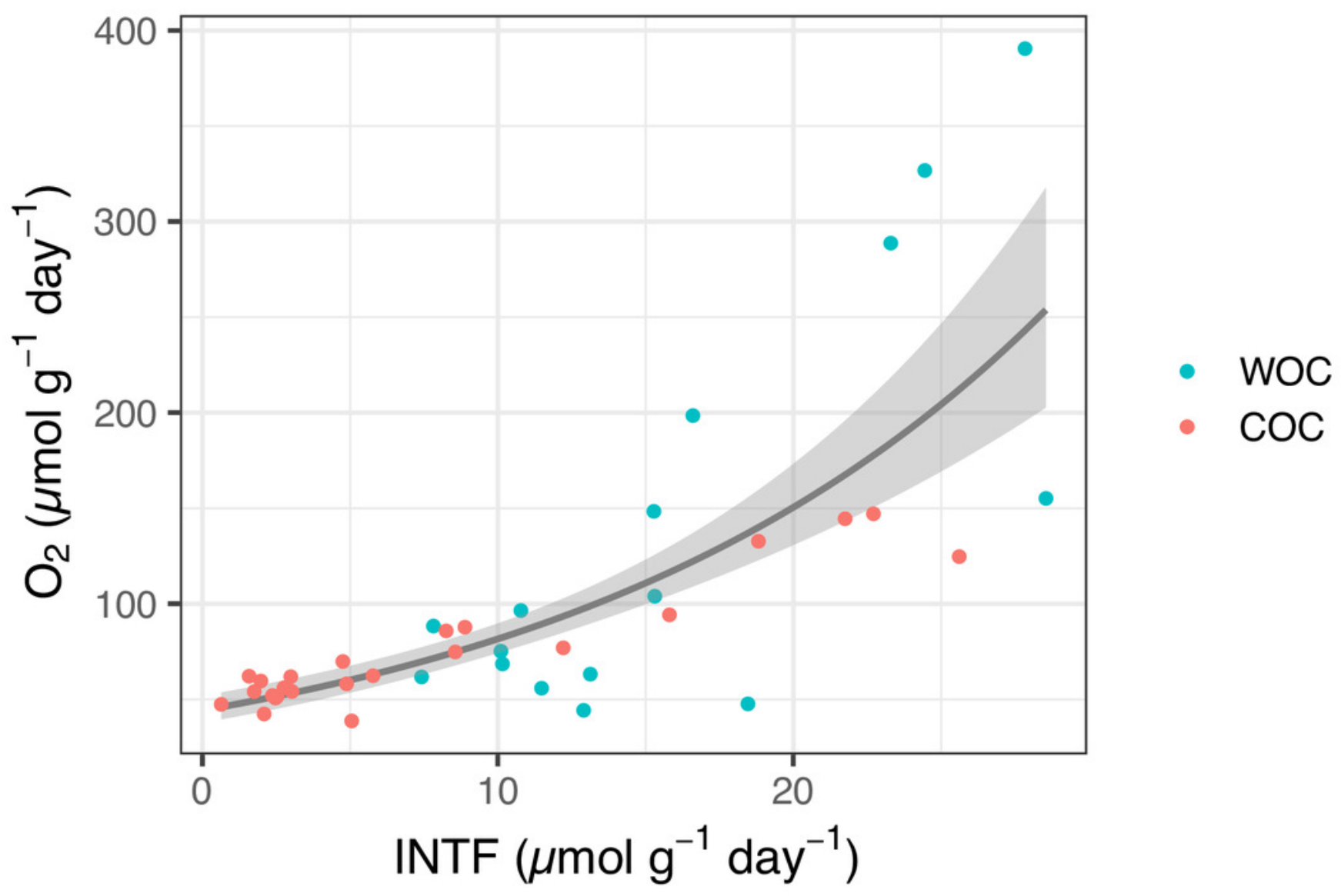


Figure 2

Sediment oxygen consumption rate ( $\mathrm{mmol}$ INTF $\left.\mathrm{m}^{-2} \mathrm{day}^{-1}\right)$ measured with the INT reduction method for (A) 2011, (B) 2012, and (C) 2013.

Error bar of potential WOC ( $\left.\mathrm{pWOC}_{\mathrm{INT}}\right)$ represents the standard error $(\mathrm{n}=3)$. Error bar for potential $\mathrm{COC}\left(\mathrm{pCOC}_{\mathrm{INT}}\right)$ represents the range of duplicate measurements from July 2011 through July 2012. Error bars of pCOC $_{\mathrm{INT}}$ represent the standard error after August 2012 $(n=3)$. Note that the $y$-axis scale is different among figures. Potential sediment oxygen consumption for 2011 and $\mathrm{pCOC}_{\mathrm{INT}}$ for 2013 were calculated using the INT reduction rate obtained from Mori et al, (2015). (D) shows the relative abundance of the Arcobacter group before and after 24 hours of re-oxygenation incubation in 2012.
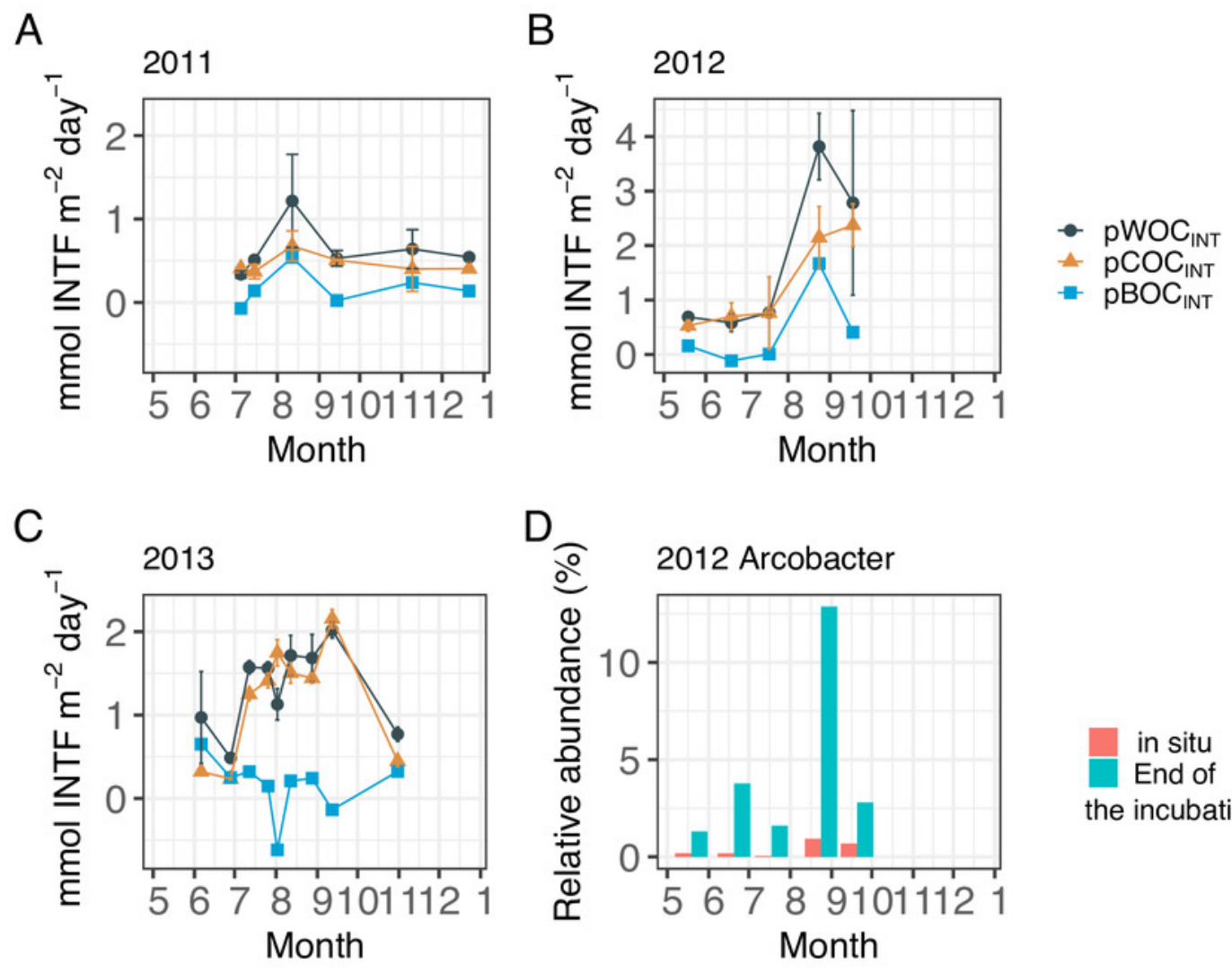

in situ

End of the incubation 


\section{Figure 3}

The results of principal component analysis (PCA) and a generalized linear model (GLM) using abiotic environmental factors and pSOC.

The GLM used a gamma distribution with a log-link function. The fitted lines represent the mean response, and the shaded area indicates the $95 \%$ quantiles of the marginal distribution. (A) The first two principal components. The arrow length indicates the variance of the variable, and the arrow direction indicates increasing values. Arrows pointing in the same direction indicate positive correlations, and arrows pointing in opposite directions indicate negative correlations. The degree of correlation is indicated by the angle between any two arrows, where a right- angle indicates no correlation. (B) $\mathrm{pWOC}_{\mathrm{INT}}$ (C) $\mathrm{pBOC}_{\mathrm{NT}}$, and (D) $\mathrm{pCOC}_{\mathbb{N T}}$ were only significantly affected by the second principal component $\left(\mathrm{pWOC}_{\mathbb{N} T}, \mathrm{P}=\right.$ $0.007 ; \mathrm{PBOC}_{\mathbb{N N T}}, \mathrm{P}=0.570 ; \mathrm{pCOC}_{\mathrm{NT}}, \mathrm{P}=0.001$ ). Negative $\mathrm{PBOC}_{\mathrm{NTT}}$ values were omitted when GLM analysis was applied. 

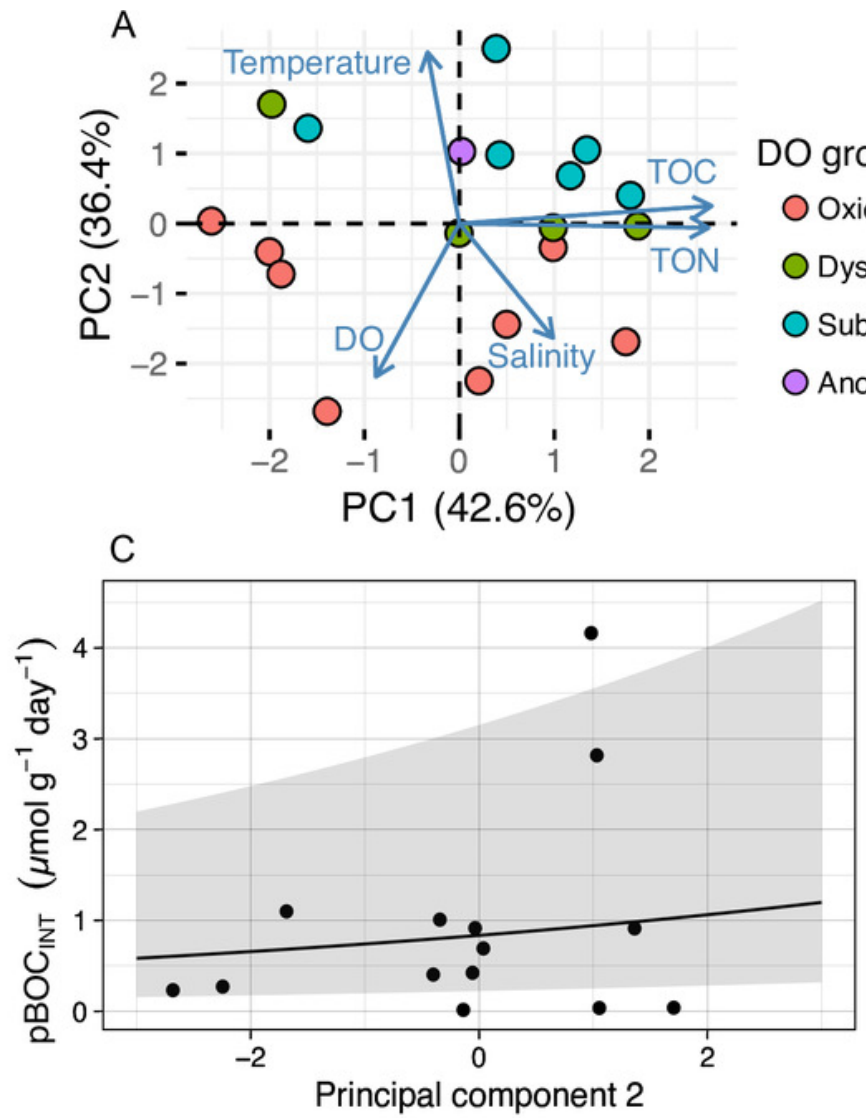
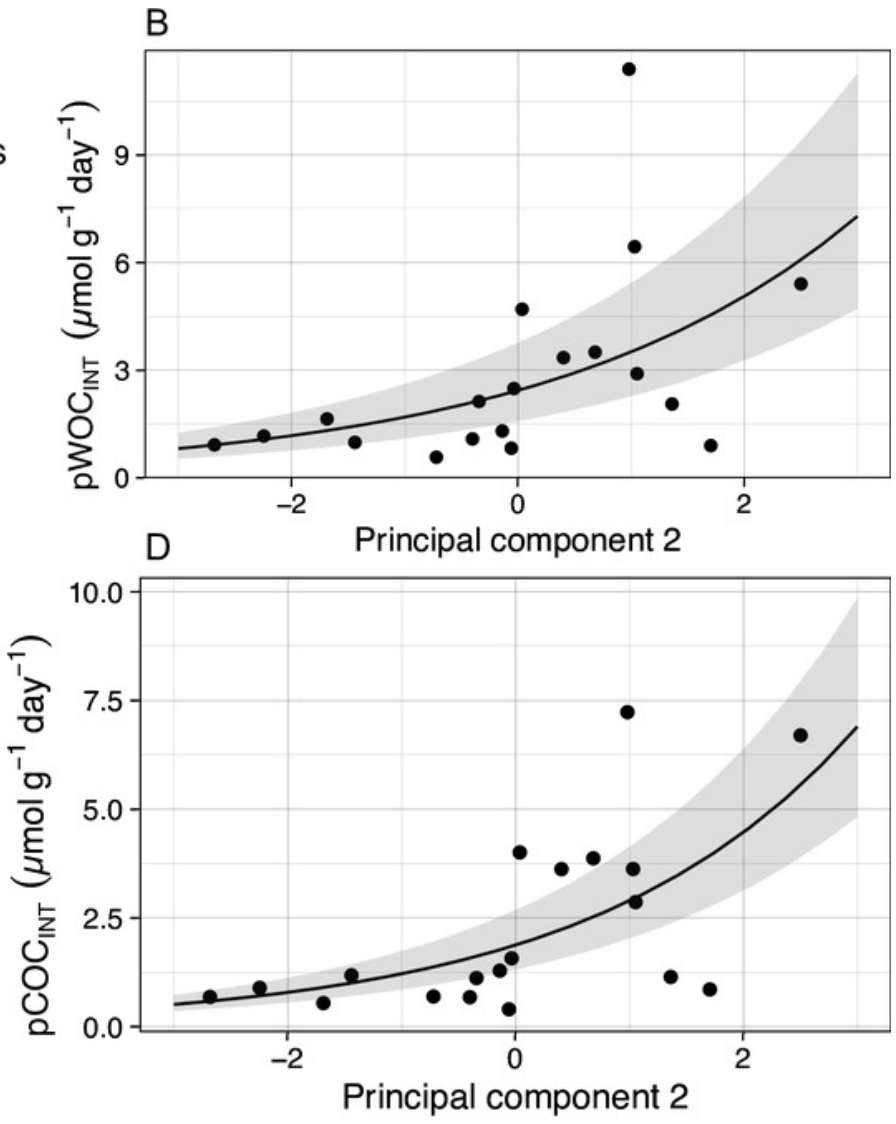


\section{Figure 4}

Stacked bar graphs of bacterial community composition from (A) the start and (B) the end of the reoxygenated incubation experiment for INT reduction measurement.

The partial 16S rRNA gene amplicons show the relative abundance (\%) of counts. Groups demonstrating $<1 \%$ abundance were summarized as " $<1 \%$ abundance".

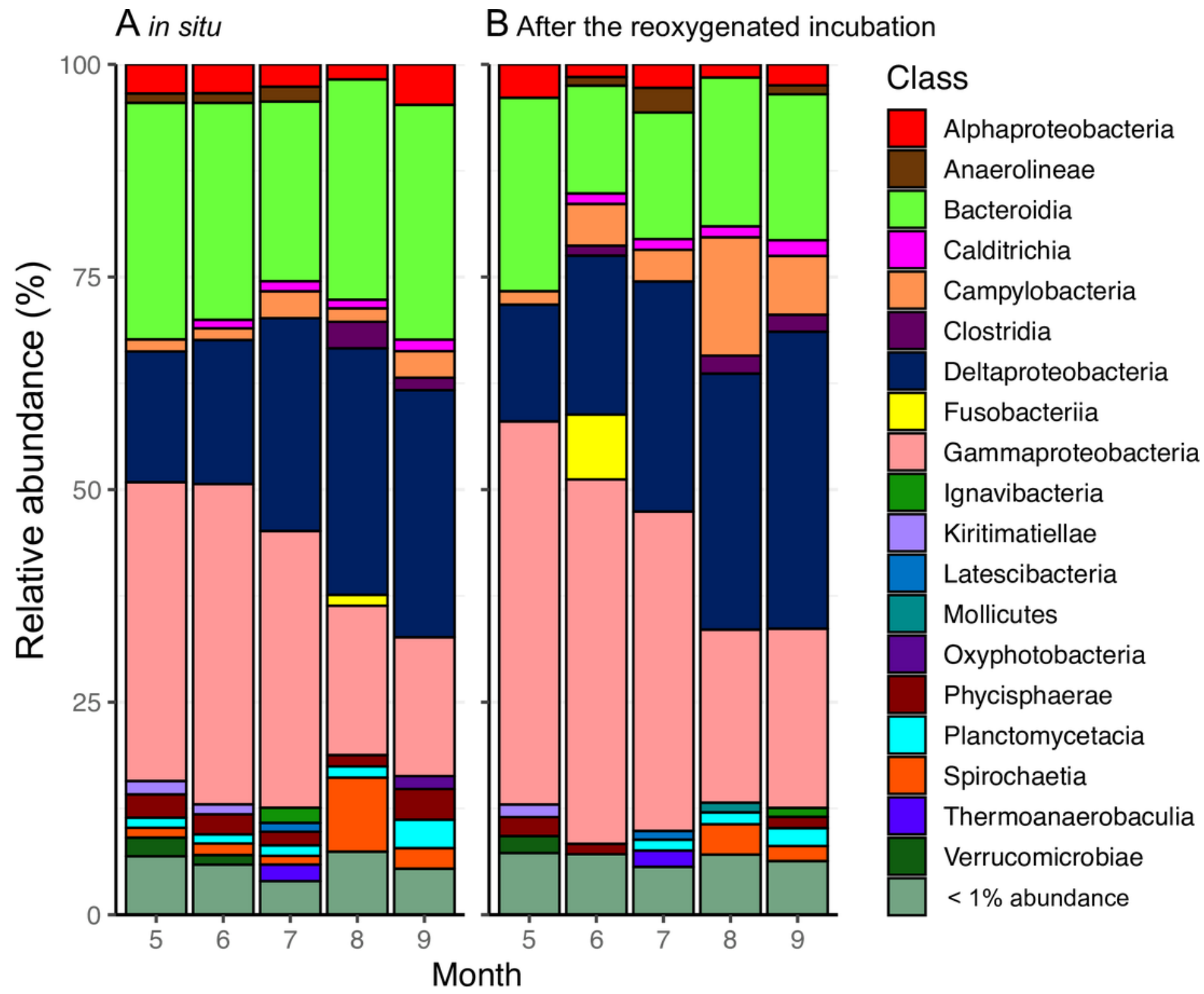




\section{Figure 5}

Hierarchical clustering of the bacterial community composition in the sediment samples.

The distance matrix was calculated based on the Bray-Curtis dissimilarity, and clusters were calculated using Ward's method. Open symbols indicate samples that were collected at the start of the incubation experiment. Closed symbols indicate samples that were collected at the end of incubation experiment. The symbols indicate the oxygen conditions in the bottom water (circle, oxic conditions; triangle, dysoxic conditions; and star, anoxic conditions). 


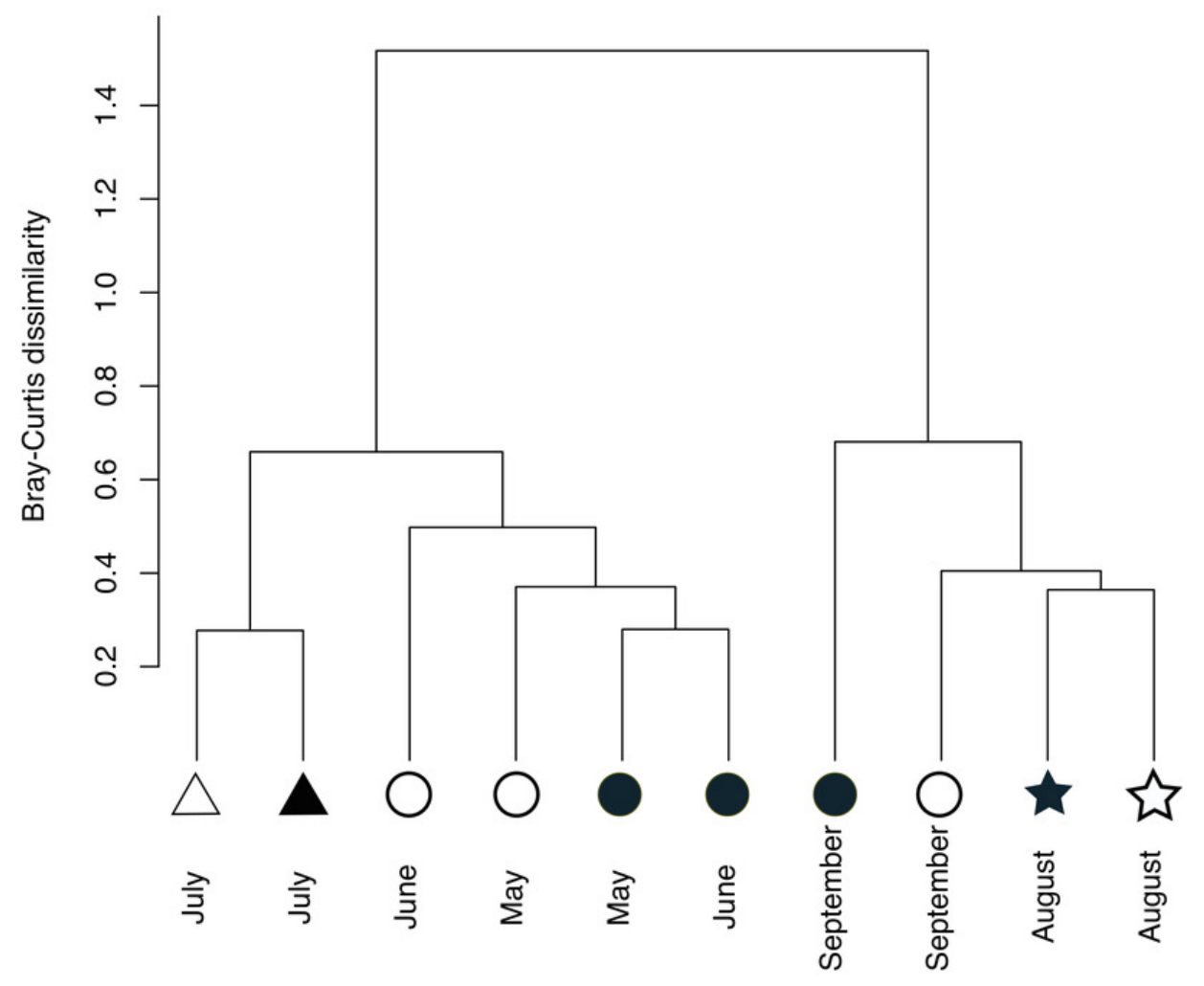




\section{Figure 6}

Potential oxygen consumption and community composition of sediment bacteria in a seasonally hypoxic enclosed bay Bar plot of the top ten families showing an increase $(A)$ or decrease (B) 24 hours after oxygenation in 2012.

Potential oxygen consumption and community composition of sediment bacteria in a seasonally hypoxic enclosed bay. The percentage of change was calculated by subtracting the relative abundance at the end of the incubation from that of in situ sediment samples. Dissolved oxygen condition at the site has been showing, according to the criteria used by

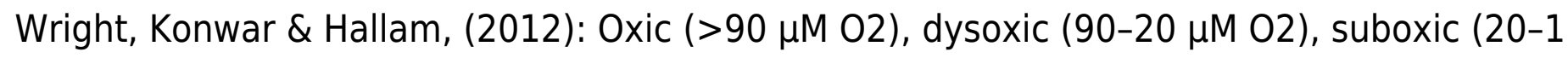

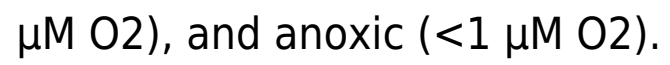


A Increase in relative abundance (\%)

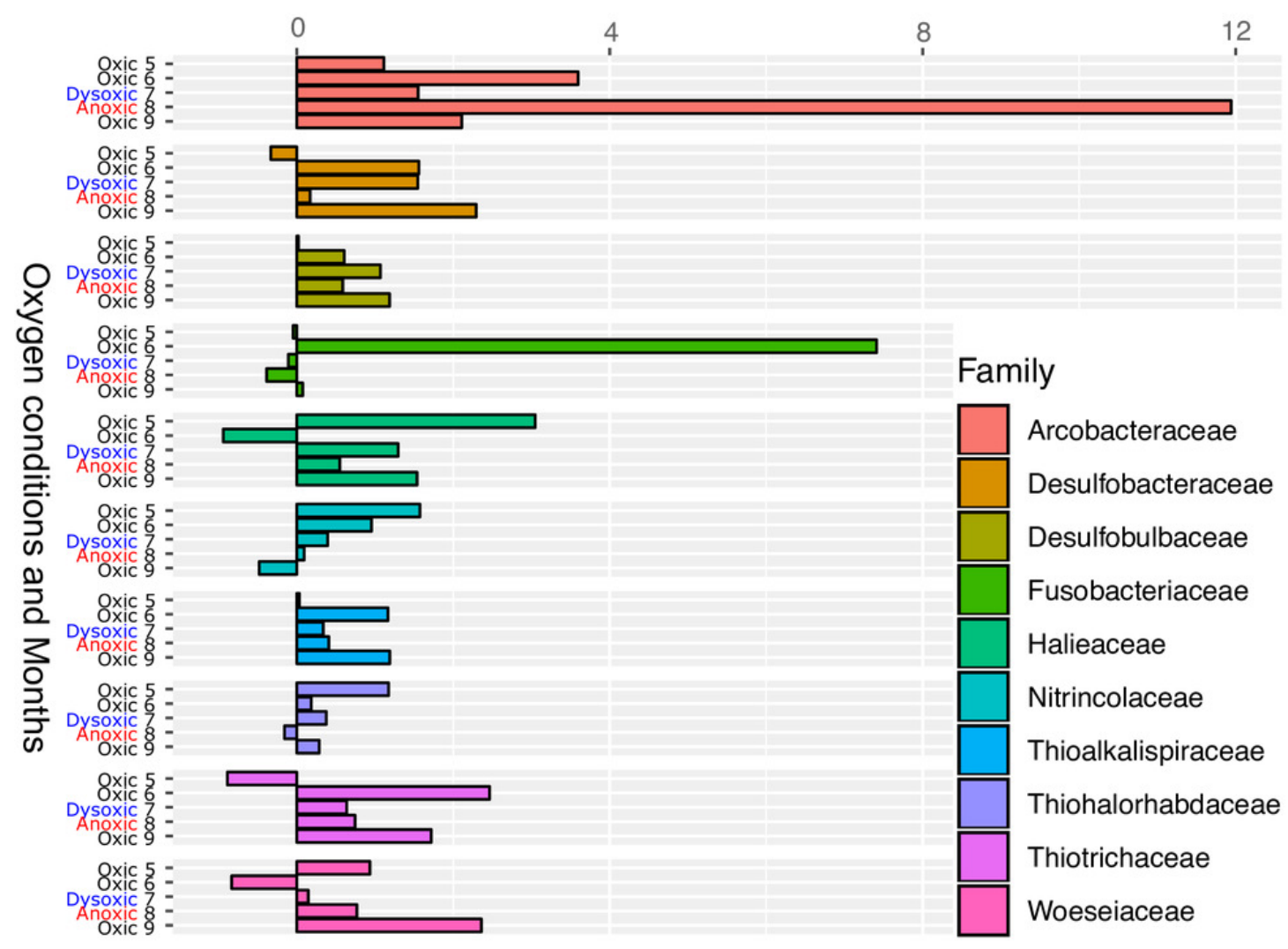

B

Decrease in abundance (\%)

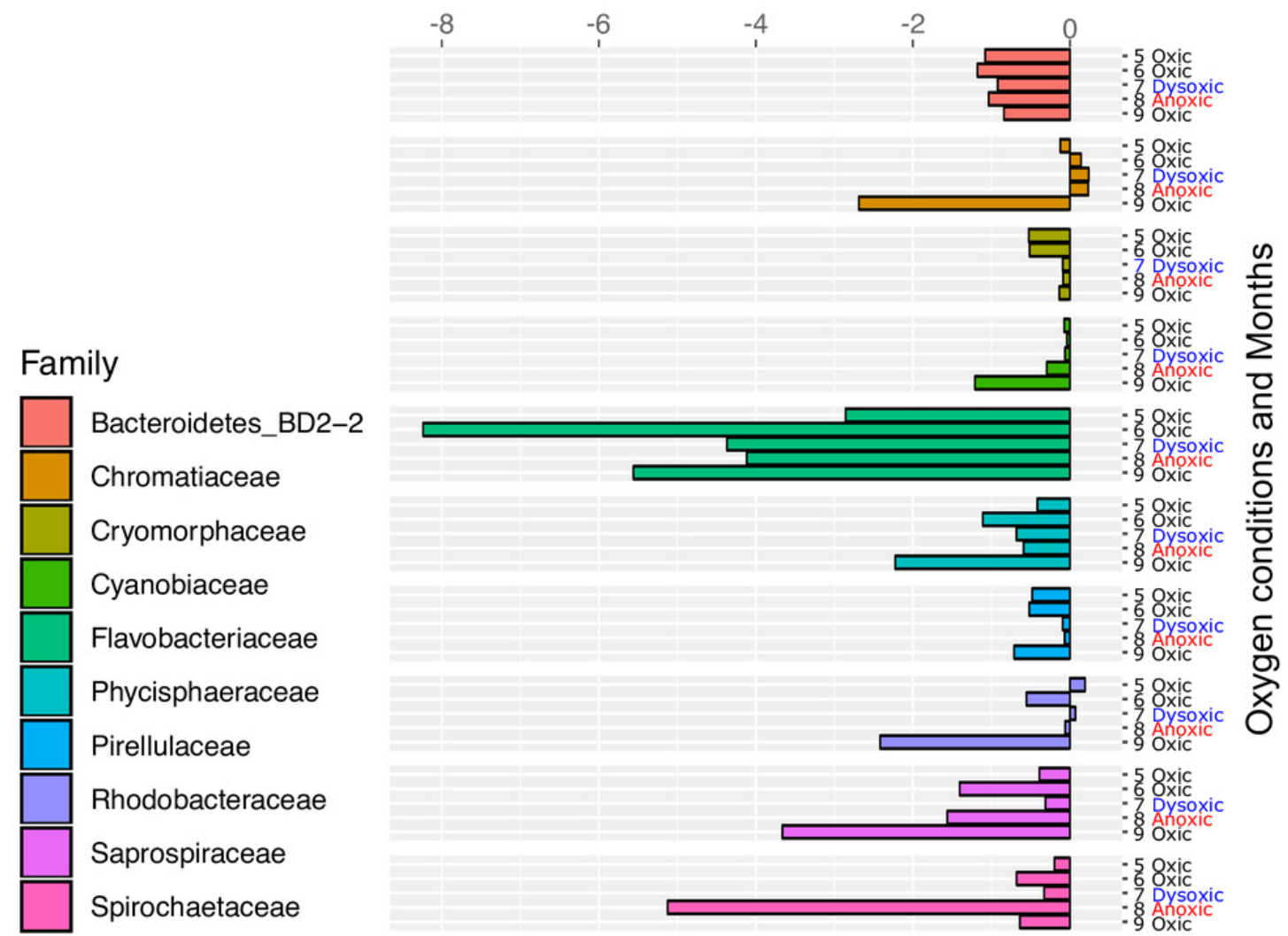




\section{Table $\mathbf{1}$ (on next page)}

Dissolved oxygen (DO) conditions in the bottom water and potential oxygen consumption in the sediment of Omura Bay, Japan.

Environmental parameters and some INT reduction rate data were obtained from Mori et al, (2015, 2018b). DO concentration was divided into four categories, according to the criteria used by Wright, Konwar \& Hallam, (2012): Oxic (>90 $\left.\mu \mathrm{M} \mathrm{O} \mathrm{O}_{2}\right)$, dysoxic $\left(90-20 \mu \mathrm{M} \mathrm{O}_{2}\right)$, suboxic $\left(20-1 \mu \mathrm{M} \mathrm{O}_{2}\right)$, and anoxic $\left(<1 \mu \mathrm{M} \mathrm{O} \mathrm{O}_{2}\right)$. 


\begin{tabular}{|c|c|c|c|c|c|c|c|c|c|c|c|c|c|}
\hline \multirow[b]{2}{*}{ Year } & \multirow[b]{2}{*}{$\begin{array}{l}\text { Month } \\
\text { /Day }\end{array}$} & \multicolumn{4}{|c|}{ Bottom water } & \multicolumn{8}{|c|}{ Sediment } \\
\hline & & $\begin{array}{c}\text { DO } \\
\text { conditions }\end{array}$ & $\begin{array}{c}\mathrm{DO} \\
(\mu \mathrm{M})^{\dagger}\end{array}$ & $\begin{array}{c}\text { Temperature } \\
\left({ }^{\circ} \mathrm{C}\right)^{\dagger}\end{array}$ & $\begin{array}{l}\text { Salinity } \\
\text { (PSU) }{ }^{\dagger}\end{array}$ & $\sqsubset$ & $\begin{array}{c}\mathrm{pWOC}_{\mathrm{INT}} \\
\left(\mu \mathrm{mol} \mathrm{g} \mathrm{day}^{-1}\right)\end{array}$ & $\begin{array}{c}\mathrm{pCOC}_{\mathrm{INT}} \\
\left(\mu \mathrm{mol} \mathrm{g}{ }^{-1} \text { day }^{-1}\right)\end{array}$ & $\begin{array}{c}\mathrm{pBOC} \\
\left(\mu \mathrm{mol} \mathrm{g}^{-1} \text { day }^{-1}\right)\end{array}$ & $\begin{array}{c}\text { TOC } \\
\left(\mathrm{mg} \mathrm{g}^{-1}\right)^{\dagger}\end{array}$ & $\begin{array}{c}\text { TON } \\
\left(\mathrm{mg} \mathrm{g}^{-1}\right)\end{array}$ & $\begin{array}{c}\text { Sulfide } \\
\left(\mathrm{mg} \mathrm{S} \mathrm{g}^{-1}\right)^{\dagger}\end{array}$ & $\begin{array}{c}\text { Bacterial cells } \\
\text { abundance } \\
(\text { Cells g-1 })^{\dagger}\end{array}$ \\
\hline \multirow{6}{*}{2011} & $7 / 5$ & Dysoxic & 70.4 & 20.1 & 32.6 & & $0.57 *$ & $0.69 *$ & -0.12 & 24.1 & 2.6 & NA & $6.3 \times 10^{9}$ \\
\hline & $7 / 15$ & Dysoxic & 65.2 & 21.0 & 31.2 & & $0.86^{*}$ & $0.62 *$ & 0.24 & NA & NA & NA & $6.0 \times 10^{9}$ \\
\hline & $8 / 12$ & Suboxic & 4.8 & 24.5 & 30.3 & & $2.05^{*}$ & $1.14^{*}$ & 0.91 & 26.1 & 2.9 & NA & $7.2 \times 10^{9}$ \\
\hline & $9 / 14$ & Dysoxic & 44.3 & 25.6 & 28.9 & & $0.89 *$ & $0.86^{*}$ & 0.04 & 25.7 & 3.0 & NA & $7.2 \times 10^{9}$ \\
\hline & $11 / 9$ & Oxic & 128.7 & 22.0 & 31.3 & & $1.08^{*}$ & $0.68^{*}$ & 0.40 & 24.8 & 2.8 & NA & $7.6 \times 10^{9}$ \\
\hline & $12 / 21$ & Oxic & 243.3 & 14.0 & 31.1 & & $0.91 *$ & $0.68 *$ & 0.23 & 26.7 & 3.3 & NA & $4.3 \times 10^{9}$ \\
\hline \multirow{5}{*}{2012} & $5 / 19$ & Oxic & 157.6 & 15.7 & 32.9 & & 1.16 & 0.89 & 0.27 & 31.3 & 3.7 & NA & $6.1 \times 10^{10}$ \\
\hline & $6 / 20$ & Oxic & 124.0 & 19.0 & 33.1 & & 0.98 & 1.18 & -0.20 & 32.2 & 3.8 & NA & $3.4 \times 10^{10}$ \\
\hline & $7 / 18$ & Dysoxic & 82.7 & 22.1 & 31.9 & & 1.30 & 1.29 & 0.01 & 33.1 & 3.4 & NA & $3.0 \times 10^{10}$ \\
\hline & $8 / 24$ & Anoxic & 0.0 & 24.1 & 31.3 & & 6.44 & 3.62 & 2.82 & 30.6 & 3.6 & NA & $1.7 \times 10^{11}$ \\
\hline & $9 / 20$ & Oxic & 195.9 & 27.3 & 31.2 & & 4.70 & 4.01 & 0.69 & 22.0 & 2.9 & NA & $1.7 \times 10^{11}$ \\
\hline \multirow{9}{*}{2013} & $6 / 6$ & Oxic & 138.2 & 17.6 & 32.9 & & 1.64 & $0.54^{*}$ & 1.10 & 37.8 & 4.3 & 0.12 & $2.5 \times 10^{10}$ \\
\hline & $6 / 28$ & Dysoxic & 70.7 & 20.8 & 31.3 & & 0.82 & $0.40 *$ & 0.42 & 36.5 & 3.9 & 0.06 & $3.0 \times 10^{10}$ \\
\hline & $7 / 12$ & Dysoxic & 53.2 & 22.7 & 32.8 & & 2.49 & $1.57^{*}$ & 0.91 & 39.5 & 4.1 & 0.02 & $3.2 \times 10^{10}$ \\
\hline & $7 / 26$ & Suboxic & 1.6 & 22.3 & 30.4 & & 2.90 & $2.86^{*}$ & 0.04 & 37.4 & 4.1 & 0.32 & $3.1 \times 10^{10}$ \\
\hline & $8 / 2$ & Suboxic & 1.8 & 22.8 & 32.7 & & 3.35 & $3.62 *$ & -0.28 & 38.3 & 4.1 & 0.37 & $2.5 \times 10^{10}$ \\
\hline & $8 / 12$ & Suboxic & 8.0 & 24.6 & 32.6 & & 3.50 & $3.87 *$ & -0.37 & 35.3 & 3.9 & 0.52 & $2.8 \times 10^{10}$ \\
\hline & $8 / 28$ & Suboxic & 3.1 & 26.4 & 32.7 & & 11.39 & $7.23 *$ & 4.16 & 31.8 & 3.7 & 0.44 & $3.2 \times 10^{10}$ \\
\hline & $9 / 12$ & Suboxic & 2.9 & 26.9 & 28.5 & & 5.40 & $6.70 *$ & -1.29 & 36.4 & 3.8 & 0.43 & $2.7 \times 10^{10}$ \\
\hline & $10 / 31$ & Oxic & 166.7 & 22.1 & 30.6 & $\sqsubset$ & 2.12 & 1.12 & 1.01 & 37.0 & 4.2 & 0.03 & $3.2 \times 10^{10}$ \\
\hline
\end{tabular}

17 
pWOC ${ }_{\mathrm{INT}}$ : potential whole oxygen consumption, $\mathrm{pCOC}_{\mathrm{INT}}$ : potential chemical oxygen consumption, $\mathrm{pBOC}$ INT: potential biological oxygen consumption, TOC: total organic carobn, TON: total organic nitrogen, NA: not applicable.

†; Previously published environmental parameters from Mori et al. (2015) and Mori et al. (2018b).

*; Previously published potentionl oxygen consumption rate measured with INT reduction method from Mori et al. (2015). 


\section{Table 2 (on next page)}

Descriptive statistics of the principal component (PC) scores of environmental paramters 
1

\begin{tabular}{ccccccccc}
\hline & \multicolumn{1}{c}{ Standard } & $\begin{array}{c}\text { Proportion } \\
\text { of } \\
\text { deviation }\end{array}$ & $\begin{array}{c}\text { Cumulative } \\
\text { proportion }\end{array}$ & $\begin{array}{c}\text { DO } \\
(\mu \mathrm{M})\end{array}$ & Temperature $\left({ }^{\circ} \mathrm{C}\right)$ & Salinity (PSU) & $\begin{array}{c}\text { TOC } \\
\left(\mathrm{mg} \mathrm{g}^{-}\right.\end{array}$ & $\begin{array}{c}\text { TON } \\
\left(\mathrm{mg} \mathrm{g}^{-1}\right)\end{array}$ \\
\hline PCs & 1.46 & 0.43 & 0.43 & -0.221 & -.884 & 0.248 & 0.668 & 0.66 \\
PC2 & 1.35 & 0.36 & 0.79 & -0.595 & 0.666 & -0.444 & 0.068 & -0.017 \\
PC3 & 0.85 & 0.14 & 0.93 & 0.430 & -0.181 & -0.829 & 0.183 & 0.248 \\
\hline
\end{tabular}

2 
Table 3 (on next page)

Results of generalized linear models for PSOC and PCs. 
1

\begin{tabular}{|c|c|c|c|c|c|}
\hline Response variable & Explanatory variable & Estimate & Std.error & $\mathrm{t}$ value & $\mathrm{p}$ value \\
\hline & PC1 & 0.071 & 0.108 & 0.660 & 0.519 \\
\hline \multirow[t]{3}{*}{$\mathrm{pWOC}_{\mathrm{INT}}$} & PC2 & 0.366 & 0.116 & 3.145 & 0.007 \\
\hline & PC3 & -0.220 & 0.185 & -1.185 & 0.254 \\
\hline & PC1 & 0.037 & 0.102 & 0.365 & 0.721 \\
\hline \multirow[t]{3}{*}{$\mathrm{pCOC}_{\mathrm{INT}}$} & PC2 & 0.434 & 0.120 & 3.948 & 0.001 \\
\hline & PC3 & -0.205 & 0.175 & -1.169 & 0.260 \\
\hline & PC1 & 0.245 & 0.172 & 1.424 & 0.185 \\
\hline \multirow[t]{2}{*}{$\mathrm{pBOC}_{\mathrm{INT}}$} & $\mathrm{PC} 2$ & 0.120 & 0.205 & 0.588 & 0.570 \\
\hline & $\mathrm{PC} 3$ & -0.618 & 0.362 & -1.709 & 0.118 \\
\hline
\end{tabular}

2 Bold indicates a significant value at the $\mathrm{p}<0.05$ level. 